JUNIOR OLIVEIRA, A. F. de et al. Caracterização dos serviços ecossistêmicos de amenidades e cultura no Parque Nacional da Serra da Canastra e seu entorno

\title{
CARACTERIZAÇÃO DOS SERVIÇOS ECOSSISTÊMICOS DE AMENIDADES E CULTURA NO PARQUE NACIONAL DA SERRA DA CANASTRA E SEU ENTORNO ${ }^{1}$
}

\author{
Arnaldo Freitas de Oliveira Junior ${ }^{2}$ \\ Fabrício Teixeira de $\mathrm{Melo}^{3}$ \\ Fulvio Cupolillo ${ }^{4}$ \\ Márcia Aparecida Silva ${ }^{5}$ \\ Neimar de Freitas Duarte ${ }^{6}$ \\ Rodrigo Ribeiro Pignaton ${ }^{7}$ \\ Walter Bruno de Oliveira Minucci ${ }^{8}$
}

\begin{abstract}
RESUMO
Os serviços ambientais são integrantes do desenvolvimento da humanidade. Os serviços do Parque Nacional da Serra da Canastra por sua vez são responsáveis pelo fornecimento de serviços ecossistêmicos, dentre os quais podemos citar os serviços culturais como recreação, valores espirituais e estéticos, educação ambiental bem como serviços de amenidades como bem-estar e alto nível de qualidade de vida da população do entorno. Dessa forma, avaliouse a percepção dos turistas em relação aos benefícios providos pelo Parque e de forma simplória valorizou seus serviços ambientais, principalmente os culturais e de amenidades. Como resultado dessa percepção, verificou-se que o custo predominante de hospedagem na região da Serra da Canastra varia de $\mathrm{R} \$ 151,00$ a $\mathrm{R} \$ 200,00$ para o casal/dia, quanto ao custo de alimentação é de até R $\$ 150,00$ para o casal/dia. O perfil da renda familiar dos entrevistados mostrou-se acima de R \$ 3001,00 reais. Por fim, os Pagamentos por Serviços Ambientais - PSA, tanto providos pela política pública e/ou privada, são capazes de proporcionar um aumento na renda dos proprietários rurais e outros do entorno do PNSC.
\end{abstract}

Palavras-chaves: Amenidades. Cultura. Unidade de conservação.

\footnotetext{
${ }^{1}$ Como citar este artigo:

JUNIOR OLIVEIRA, A. F. de et al. Caracterização dos serviços ecossistêmicos de amenidades e cultura no Parque Nacional da Serra da Canastra e seu entorno. ForScience: revista científica do IFMG, Formiga, v. 5, n. 2, e 00192, out. 2017. Edição especial.

${ }^{2}$ Doutorado em Ecologia e Recursos Naturais pela Universidade Federal de São Carlos (UFSCar). Professor em
dedicação exclusiva do Centro Federal de Educação Tecnológica de Minas Gerais (CEFET-MG). Professor de
Desenvolvimento Sustentável pelo Instituto Federal de Minas Gerais (IFMG) - Campus Bambuí. Currículo
Lattes: http://lattes.cnpq.br/2754961037728092. E-mail: arnaldojun @ gmail.com.
${ }^{3}$ Mestrando em Sustentabilidade e Tecnologias Ambientais pelo IFMG - Campus Bambuí. Currículo Lattes:
http://lattes.cnpq.br/9115724850700784. E-mail: fabricio.melo@ @av.eng.br.
${ }^{4}$ Doutorado em Geografia pela Universidade Federal de Minas Gerais (UFMG). Coordenador de Pesquisa e
professor do IFMG. Currículo Lattes: http://lattes.cnpq.br/9611439208194168. E-mail:
fulvio.cupolillo@ ifmg.edu.br.
${ }^{5}$ Mestranda em Sustentabilidade e Tecnologias Ambientais pelo IFMG - Campus Bambuí. Currículo Lattes:
http://lattes.cnpq.br/7394741913703026. E-mail: marciabrasilmg@ gmail.com.
${ }^{6}$ Doutorado em Biologia Vegetal pela UFMG. Diretor de Pesquisa e Pós-Graduação do IFMG e professor do
IFMG. Currículo Lattes: http://lattes.cnpq.br/3416823923702282. E-mail: neimar.freitas@ ifmg.edu.br.
${ }^{7}$ Mestrando em Sustentabilidade e Tecnologias Ambientais pelo IFMG - Campus Bambuí. Currículo Lattes:
http://lattes.cnpq.br/8912500047993317. E-mail: rodrigo.abes@ gmail.com.
${ }^{8}$ Mestrando em Sustentabilidade e Tecnologias Ambientais pelo IFMG - Campus Bambuí Lattes:
http://lattes.cnpq.br/8014353437876823. E-mail: wbminucci@ gmail.com.
}

ForSci.: r. cient. IFMG, Formiga, v. 5, n. 2, e00192, out. 2017. Edição especial. 
JUNIOR OLIVEIRA, A. F. de et al. Caracterização dos serviços ecossistêmicos de amenidades e cultura no Parque Nacional da Serra da Canastra e seu entorno

\section{INTRODUÇÃO}

Os serviços ambientais são integrantes do desenvolvimento da humanidade, assim como aponta Andrade e Romeiro (2009) parte-se do princípio de que a atividade econômica, a qualidade de vida e a coesão das sociedades humanas são profundas e irremediavelmente dependentes dos serviços gerados pelos ecossistemas, sendo premente o estudo da dinâmica de geração dos serviços ecossistêmicos e suas interações com as variáveis humanas. Descreve ainda que o interesse pelos ecossistemas e por seus serviços têm aumentado exponencialmente nos últimos anos (ANDRADE; ROMEIRO, 2009). As funções ecossistêmicas são extremamente relevantes, pois, é por meio delas que se dá a geração dos chamados serviços ecossistêmicos, que são os benefícios diretos e indiretos obtidos pelo homem a partir dos ecossistemas (ANDRADE, ROMEIRO, 2009). Enquanto, Millennium Assessment (2003, apud PARRON et al., 2015) classifica os serviços culturais como os benefícios imateriais obtidos dos ecossistemas, que contribuem para o bem-estar da população, como a própria cultura ambiental, ainda, o turismo ambiental.

O ecossistema escolhido foi o Parque Nacional da Serra da Canastra (PNSC), localizado no Circuito Canastra, sudoeste do Estado de Minas Gerais abrange 6 (seis) municípios: São Roque de Minas, Sacramento, Delfinópolis, São João Batista do Glória, Capitólio e Vargem Bonita, e é responsável pelo fornecimento de serviços ecossistêmicos, dentre os quais podemos citar os serviços culturais como recreação, valores espirituais e estéticos, educação ambiental bem como serviços de amenidades como bem estar e alto nível de qualidade de vida da população do entorno.

Conforme destacado pelo Ministério do Meio Ambiente (MMA 2005), o Circuito Canastra emerge como uma alternativa de desenvolvimento econômico, por meio da iniciativa do Instituto Brasileiro de Turismo (Embratur) e da Empresa Mineira de Turismo (Turminas), amplamente divulgado pela mídia e desenvolvido nos municípios de Araxá, Bambuí, Campos Altos, Ibiá, Sacramento, São Roque de Minas, Tapira e Tapiraí, apresentando como grande atrativo a diversificação turística.

Com o advento do ecoturismo, vária foram as alternativas de desenvolvimento encontradas pela população local, as quais têm trazido benefícios sociais e financeiros para a região, como a geração de empregos, diversificação das atividades econômicas, além do atendimento à demanda de visitantes da região e do Parque, ainda que de forma incipiente. Como exemplo destas alternativas podemos citar a adaptação e utilização de propriedades particulares como meios de hospedagem (pousadas, hotéis-fazenda e campings), onde, normalmente, é 
JUNIOR OLIVEIRA, A. F. de et al. Caracterização dos serviços ecossistêmicos de amenidades e cultura no Parque Nacional da Serra da Canastra e seu entorno

empregada a mão-de- obra familiar, sendo em alguns casos, contratados funcionários temporários, para a alta estação. São oferecidas, geralmente, refeições caseiras com comidas regionais, além de cobrança de taxas suplementares para visita aos atrativos naturais, bem como para outros serviços, como, por exemplo, guiamento de visitantes (MMA, p. 245, 2005).

De acordo com MMA (2005), os serviços de hospedagem e alimentação foram os que mais cresceram no entorno do PNSC, tanto em quantidade, quanto em qualidade. Alguns produtos regionais como o queijo canastra, doces, farinha e o artesanato, conforme levantado por MMA (2005) são alternativas de desenvolvimento dos municípios do entorno.

O queijo canastra vem sendo produzido na região há mais de 150 anos. Este queijo, considerado pelo Iepha como elemento do patrimônio cultural do Estado de Minas Gerais, tem se mostrado como uma das principais atividades econômicas desenvolvidas na região, especialmente na área rural. Esta informação pode ser ilustrada com dados do município de São Roque de Minas, onde existem mais de 850 queijarias, com o trabalho sendo desenvolvido, quase que exclusivamente, por mão-de-obra familiar (MMA, p. 248, 2005).

MMA (2005) afirma que a sustentabilidade dos produtos regionais será alcançada à medida que todos os processos produtivos sejam ambiental e socialmente justos e corretos.

\begin{abstract}
Os serviços culturais incluem a diversidade cultural, na medida em que a própria diversidade dos ecossistemas influencia a multiplicidade das culturas, valores religiosos e espirituais, geração de conhecimento (formal e tradicional), valores educacionais e estéticos, etc. Estes serviços estão intimamente ligados a valores e comportamentos humanos, bem como às instituições e padrões sociais, características que fazem com que a percepção dos mesmos seja contingente a diferentes grupos de indivíduos, dificultando sobremaneira a avaliação de sua provisão. Os serviços de suporte são aqueles necessários para a produção dos outros serviços ecossistêmicos. Eles se diferenciam das demais categorias na medida em que seus impactos sobre o homem são indiretos e/ou ocorrem no longo prazo. Como exemplos, pode-se citar a produção primária,16 produção de oxigênio atmosférico, formação e retenção de solo, ciclagem de nutrientes, ciclagem da água e provisão de habitat (ANDRADE; ROMEIRO, p. 78 2009).
\end{abstract}

Inúmeros são os serviços ecossistêmicos prestados ao longo do Parque Nacional Serra da Canastra, assim como afirma Parron et al. (2015), a concepção de valor dos recursos naturais apoia-se na teoria do bem-estar e dos bens públicos e no conceito de externalidades (PARRON et al. 2015), assunto a ser detalhado neste estudo. Esse trabalho possibilitou constatar a ampla área para atividades de contemplação da paisagem, experiências espirituais e cognitivas, além da realização de atividades de educação ambiental, os Serviços Ambientais associados à Cultura e Amenidades. 
JUNIOR OLIVEIRA, A. F. de et al. Caracterização dos serviços ecossistêmicos de amenidades e cultura no Parque Nacional da Serra da Canastra e seu entorno

\section{DESENVOLVIMENTO}

O levantamento dos serviços ecossistêmicos de Amenidades e Cultura do Parque Nacional da Serra da Canastra e seu entorno foi realizado através do método de Pesquisa de Campo. Para Markoni e Lakatos (1996) a pesquisa de campo deve ser realizada após o estudo bibliográfico do tema, e pode ser dos seguintes tipos: quantitativasdescritivas, exploratórias e experimentais. O tipo de pesquisa de campo utilizado neste artigo foi a quantitativa-descritiva utilizando técnicas de coleta de dados, através de registros fotográficos e entrevistas. O método da entrevista se caracteriza pela existência de um entrevistador, que faz perguntas ao entrevistado anotando as respostas. A entrevista pode ser feita individualmente, em grupo, por telefone ou pessoalmente (MATTAR, 1996).

O método de entrevista definido por Mattar (1996) foi o utilizado neste artigo. Utilizou-se a Ficha de Entrevista (APÊNDICE A) e o acervo fotográfico de "Amenidades e Cultura" ${ }^{1}$ " obtido in loco, sendo assim as fotos foram distribuídas em dois grupos de serviços ambientais, (A) Amenidades e (B) Cultura. São os benefícios imateriais obtidos dos ecossistemas, que contribuem para o bem-estar da população, como a própria cultura ambiental, ainda, o turismo ambiental, segundo Carpenter (2009).

\section{DISCUSSÃO DOS RESULTADOS}

O esforço amostral foi de quatro entrevistas com turistas, durante visita ao campo em 21/05/2016 e 35 no período de 05/08/2016 a 07/08/2016, no Parque Nacional da Serra da Canastra e seu entorno. Os resultados mostraram-se dentro de uma linha de tendência. Através das 39 entrevistas verificou-se que o custo predominante de hospedagem na região da Serra da Canastra varia de R\$ 154,00 a R\$ 208,00 para o casal/dia, quanto ao custo de alimentação é de até $\mathrm{R} \$ 152,00$ para o casal/dia. O perfil da renda familiar dos entrevistados mostrou-se acima de R \$3075,00 reais. Diante da amostragem, verifica-se uma linha de tendência exponencial correlacionada entre o Pagamento de Serviços Ambientais (PSA), caracteriza-se segundo Andrade por,

[...] uma transação voluntária, na qual, um serviço ambiental bem definido ou um uso da terra que possa assegurar este serviço é comprado por, pelo menos, um comprador de, pelo menos, um provedor, sob a condição de que o provedor garanta a provisão deste serviço (condicionalidade). (ANDRADE; ROMEIRO, p. 68, 2009). 
JUNIOR OLIVEIRA, A. F. de et al. Caracterização dos serviços ecossistêmicos de amenidades e cultura no Parque Nacional da Serra da Canastra e seu entorno

Os resultados apontaram os serviços oferecidos e a renda familiar dos turistas frequentadores do Parque e seu entorno. Ou seja, quanto mais diversos e/ou melhores são os serviços ambientais oferecidos, maior deverá ser a renda familiar dos turistas frequentadores (Gráfico 1).

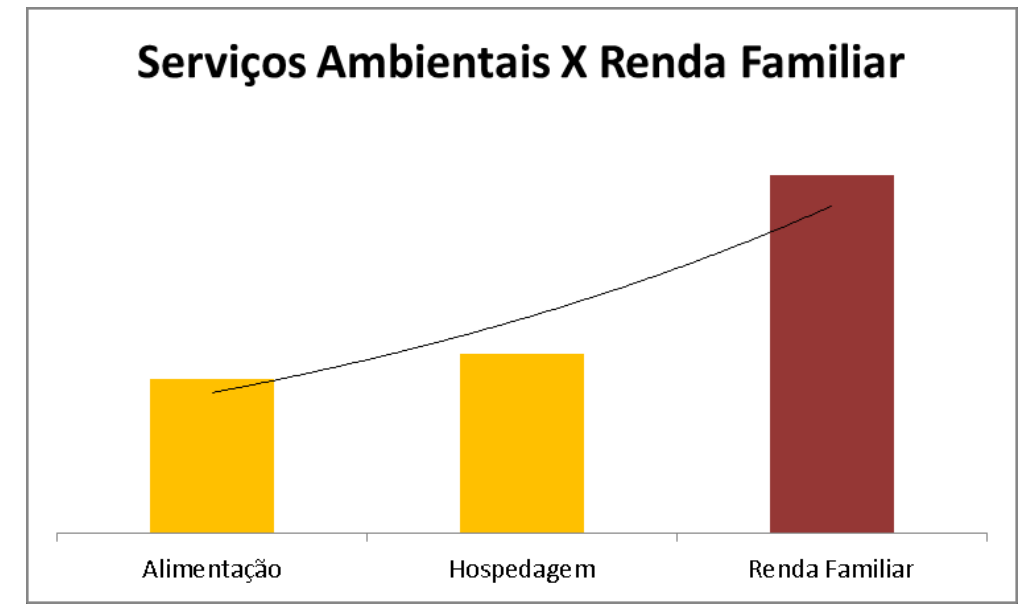

Gráfico 1- Serviços Ambientais X Renda Familiar

Nesse contexto, atingir o ótimo entre Oferta e Demanda dos Serviços Ambientais é um desafio, e não basta apenas melhorar e diversificar serviços ambientais, é necessário diminuir a desigualdade social no Brasil. Segundo Datafolha (2013), 66\% das famílias brasileiras ganha até $\mathrm{R} \$ 2.034,00$, ou seja, a desigualdade social no país é bastante significativa. No entanto, o Pagamento pelos Serviços Ambientais vem com uma proposta para a diminuição dessa desigualdade, demonstrado na figura 1 .

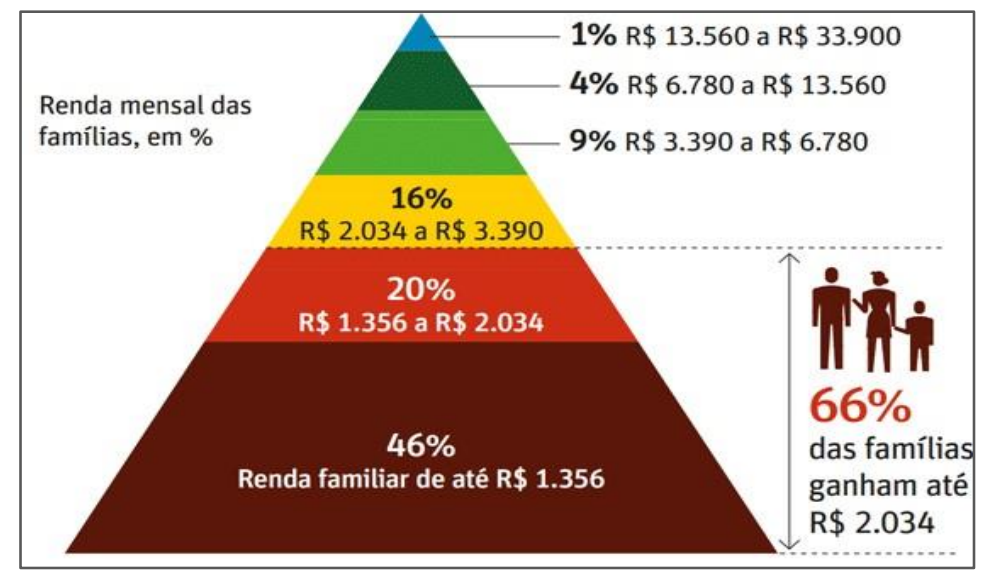

Figura 1- Pirâmide de Renda no Brasil Fonte: Carneiro (2016). 
JUNIOR OLIVEIRA, A. F. de et al. Caracterização dos serviços ecossistêmicos de amenidades e cultura no Parque Nacional da Serra da Canastra e seu entorno

Durante as entrevistas foram citados os seguintes serviços ecossistêmicos de cultura e amenidade: Culinária regional (queijo canastra), lazer, trilhas ecológicas, cultura religiosa, artesanato local e ecoturismo. Vale ressaltar que todos os entrevistados citaram o queijo canastra como serviço de cultura local.

Os serviços ecossistêmicos de cultura foram: artesanato, hotéis e pousadas, restaurantes, culinária, gastronomia, turismo em eqüinos, off Road, mountain bike e trekking. As amenidades oferecidas no Parque Nacional da Serra da Canastra e seu entorno foram: religiosidade, beleza cênica, paisagem bucólica, registro fotográfico pessoal e científico.

A seguir é apresentada a descrição e condição de conservação de todos os serviços de cultura e amenidades encontrados no PNSC e seu entorno (Tabela 2).

Tabela 2 - Serviços ecossistêmicos de cultura e amenidades do PNSC

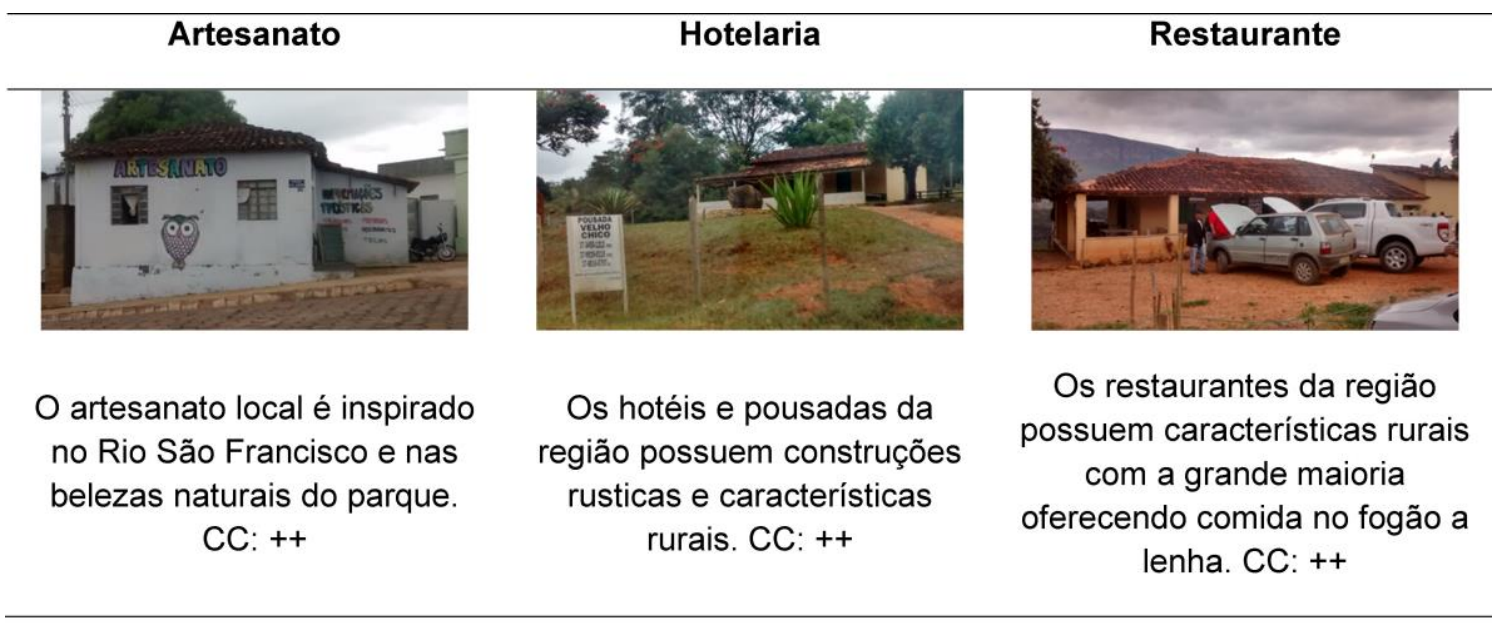

\begin{tabular}{|c|c|c|}
\hline Beleza Cênica & Cultura Religiosa & Culinária/ Gastronomia \\
\hline 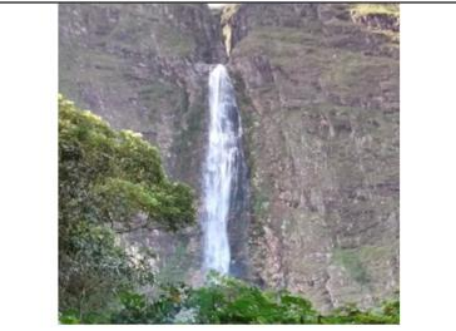 & & \\
\hline $\begin{array}{l}\text { O PNSC possui um resultado } \\
\text { visual e audível harmônico e } \\
\text { agradável formado pelo } \\
\text { conjunto dos fatores naturais } \\
\text { do local. CC: +++ }\end{array}$ & $\begin{array}{c}\text { A cultura religiosa é } \\
\text { identificada através da imagem } \\
\text { de São Francisco, próximo a } \\
\text { nascente do rio que leva o } \\
\text { mesmo nome. CC: + }\end{array}$ & $\begin{array}{c}\text { A culinária local é conhecida e } \\
\text { reconhecida nacionalmente } \\
\text { pelo queijo canastra. } \mathrm{CC}:+++\end{array}$ \\
\hline
\end{tabular}

(Continua...)

ForSci.: r. cient. IFMG, Formiga, v. 5, n. 2, e00192, out. 2017. Edição especial. 
JUNIOR OLIVEIRA, A. F. de et al. Caracterização dos serviços ecossistêmicos de amenidades e cultura no Parque Nacional da Serra da Canastra e seu entorno

(Conclusão)

Trekking

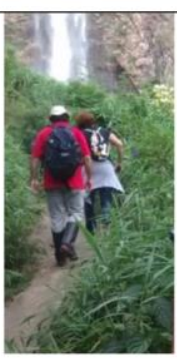

O PNSC oferece várias trilhas ecológicas cercadas de cachoeiras, montanhas.

CC: ++
Paisagem Bucólica

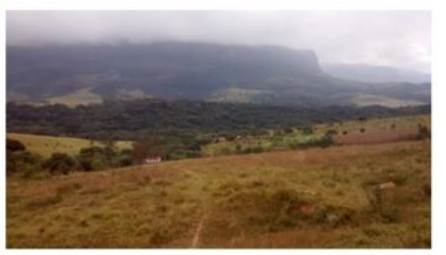

A observação de paisagens misturadas à cultura local, cachoeiras e montanhas.

$$
\text { CC: }+++
$$

\section{Fotografia da Paisagem}

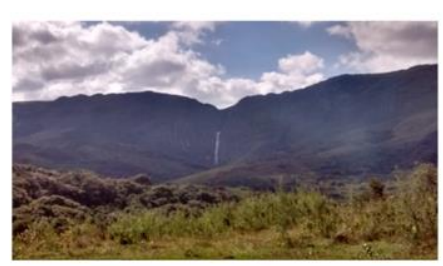

O PNSC possui imagens maravilhosas a serem

registrada. $\mathrm{CC}$ : +++

\begin{tabular}{ccc}
\hline Interação com a Fauna & Passeio Off-Road & Alojamento do PSC \\
$\begin{array}{c}\text { Registro fotográficos da fauna } \\
\text { e flora são atrativos para } \\
\text { pesquisadores, turistas e } \\
\text { estudantes. CC: ++ }\end{array}$ & $\begin{array}{c}\text { Off Road significa fora de } \\
\text { estrada, o que é típico e } \\
\text { comum na região da Serra da } \\
\text { Canastra. CC: +++ }\end{array}$ & $\begin{array}{c}\text { O PNSC disponibiliza } \\
\text { alojamento para acadêmicos e } \\
\text { afins. CC: + }\end{array}$ \\
\hline
\end{tabular}

\begin{tabular}{ccc}
\hline Espiritualidade & Camping & Mountain Bike \\
\hline $\begin{array}{c}\text { Muitos turistas visitam o PNSC } \\
\text { em busca de tranquilidade.. } \\
\text { CC: ++ }\end{array}$ & $\begin{array}{c}\text { O camping tem sido uma } \\
\text { prática frequente dos turistas. } \\
\text { CC: }++\end{array}$ & $\begin{array}{c}\text { Passeios de bicicletas tem sido } \\
\text { uma ótima opção para os } \\
\text { frequentadores do parque. CC: } \\
+++\end{array}$ \\
\hline
\end{tabular}

CC: Condição de Conservação (Usufruto): + Pouco ++Normal +++Muito

Usufruto é o direito conferido a alguém, durante certo tempo, de gozar ou fruir de um bem cuja propriedade pertence a outrem. 


\section{CONCLUSÃO}

Os Pagamentos por Serviços Ambientais, tanto providos pela política pública e/ou privada, são capazes de proporcionar um aumento na renda dos proprietários rurais e outros do entorno do Parque Nacional da Serra da Canastra. Nesse âmbito, devem-se atribuir valores econômicos aos serviços ambientais, no caso em amenidades e cultura, como forma de promover a conservação ambiental. Entretanto, uma análise ampliada sobre os dados apontados neste estudo poderá explicitar melhor o fato seguinte: a dificuldade tangível às discussões acima relaciona-se à diminuição da desigualdade social no Brasil.

\section{REFERÊNCIAS}

ANDRADE, D. C.; ROMEIRO, A. R. Serviços ecossistêmicos e sua importância para o sistema econômico e o bem-estar humano. Texto para Discussão, IE/UNICAMP, n. 155, fev. 2009. Disponível em:

<9466http://www.avesmarinhas.com.br/Servi\%C3\%A7os\%20ecossist\%C3 $\%$ AAmicos $\% 20 \mathrm{e} \% 20$ sua\%20import\%C3\%A2ncia\%20econ\%C3\%B4mica.pdf $>$. Acesso em: 25 de julho de 2016.

CARNEIRO, J. Caderno Econômico, Data Folha, São Paulo. 17 de novembro de 2013. Disponível em: www.folha.uol.com.br/colunas/carneiro/2015/07/6485868\&88 Acesso em: 19 de julho de 2016.

CARPENTER, S. R. et al. Science for managing ecosystem services: beyond the Millennium Ecosystem Assessment. Proc. Natl. Acad. Sci., U.S.A. v. 106, n. 5, p. 1305-1312, 2009.

MARCONI, M. D. A.; LAKATOS, E. M. Técnicas de pesquisa: planejamento e execução de pesquisas, amostragens e técnicas de pesquisas, elaboração, análise e interpretação de dados. 3. ed. São Paulo: Atlas, 1996.

MATTAR, F. N. Pesquisa de marketing: edição compacta. São Paulo: Atlas, 1996.

MILLENNIUM ECOSYSTEM ASSESSMENT (MA). Ecosystem and Human WellBeing: a framework for assessment. Washington, DC: Island Press, 2003.

MINISTÉRIO DO MEIO AMBIENTE (MMA). Plano de Manejo do Parque Nacional da Serra da Canastra, 2005. Disponível em:

<http://www.icmbio.gov.br/portal/images/stories/imgs-unidadescoservacao/pm_parna_serra_canastra_1.pdf>. Acesso em: 23 de julho de 2016.

PARRON, L. M. et al. Serviços ambientais em sistemas agrícolas e florestais do Bioma Mata Atlântica. Editores técnicos. Brasília, DF: Embrapa, 2015. Disponível em: 
JUNIOR OLIVEIRA, A. F. de et al. Caracterização dos serviços ecossistêmicos de amenidades e cultura no Parque Nacional da Serra da Canastra e seu entorno

<https://ainfo.cnptia.embrapa.br/digital/bitstream/item/131969/1/Livro-Servicos-

Ambientais-Embrapa.pdf>. Acesso em: 26 de julho de 2016.

\title{
CHARACTERISTICS OF ECOSYSTEM SERVICES AND AMENITIES OF CULTURE IN NATIONAL PARK CANASTRA SAW AND IT'S SURROUNDING
}

\begin{abstract}
Environmental services are integral to the development of humanity. The services of the Serra da Canastra National Park in turn are responsible for providing ecosystem services, among which we can mention cultural services such as recreation, spiritual and aesthetic values, environmental education and amenities services like welfare and high quality of life of the surrounding population. Thus, we evaluated the perception of tourists in relation to the benefits provided by the Park and simpleminded way valued environmental services, particularly cultural and amenities. As a result of this perception, it was found that the prevailing cost of hosting in the Serra da Canastra region ranges from $\mathrm{R}$ \$ 151.00 to $\mathrm{R}$ \$ 200.00 for the couple / day, and the power cost is R \$ 15000 for the double / day. The profile of the family income of respondents was shown to be above $R$ \$3,001.00 reais. Finally, the Payments for Environmental Services - PSA, both provided by the public and / or private policy, are able to provide an increase in the income of farmers and others surrounding the PNSC.
\end{abstract}

Keywords: Amenity. Culture. Conservation Unit.

\section{APENDICE A - Ficha para entrevistas aplicadas}

\begin{tabular}{|l|}
\hline Questionário 01 \\
\hline Nomes: \\
\hline Cidade: \\
\hline Objetivo da visita: \\
\hline Serviço Ecossistêmico identificado: \\
\hline Custo com alimentação do casal por dia: \\
( ) Até $R \$ 100,00$ \\
( ) De 101,00 até $R \$ 150,00$ \\
( ) De 151,00 até $R \$ 200,00$ \\
( ) Acima de $R \$ 201,00$ \\
\hline Custo com hospedagem do casal por dia: \\
( ) Até $R \$ 150,00$ \\
( ) De 151,00 até $R \$ 200,00$ \\
( ) De 201,00 até $R \$ 250,00$ \\
( ) Acima de $R \$ 251,00$ \\
\hline
\end{tabular}

ForSci.: r. cient. IFMG, Formiga, v. 5, n. 2, e00192, out. 2017. Edição especial. 
JUNIOR OLIVEIRA, A. F. de et al. Caracterização dos serviços ecossistêmicos de amenidades e cultura no Parque Nacional da Serra da Canastra e seu entorno

\section{Renda}

familiar:

( ) Até R\$1500,00

( ) De 1501,00 até R\$3000,00

( ) De 3001,00 até $\mathrm{R} \$ 5000,00$

( ) Acima de $\mathrm{R} \$ 5001,00$

Submetido em: 24/06/2016

Aprovado em: 15/07/2016

Publicado em: 06/10/2017 